\title{
Notas sobre o Trabalho Social cubano
}

\author{
Notes on Cuban social work
}

\author{
José Fernando Siqueira da Silva* \\ Onilda Alves do Carmo**
}

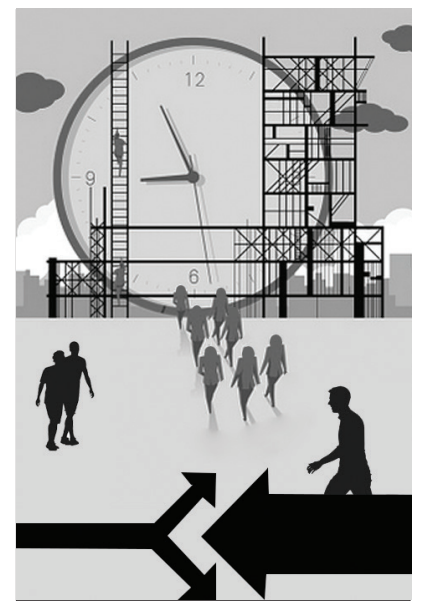

Resumo: O presente texto analisa o Trabalho Social em Cuba, seus desafios e perspectivas. Destaca, ainda, caminhos e possibilidades para reafirmar a atualidade do debate crítico entre os trabalhadores sociais cubanos e sua necessária interlocução com a teoria social de Marx.

Palavras-chave: Transição socialista. Teoria social de Marx. Trabalho Social.

\begin{abstract}
This paper analyses social work in Cuba, its challenges and perspectives. It also emphasizes ways and possibilities to reaffirm the present importance of critical debate among Cuban social worker and the necessary dialogue with Marx's social theory.
\end{abstract}

Keywords: Social transition. Marx’s social theory. Social Work.

* Assistente social, doutor em Serviço Social pela PUC e livre-docente em Serviço Social pela Unesp, professor da Unesp-Franca/SP, Brasil; bolsista Produtividade em Pesquisa do CNPq e líder do Grupo de Estudos Teoria Social de Marx e Serviço Social. Autor de Justiceiros e violência urbana e Serviço Social: resistência e emancipação?, ambos publicados pela Cortez Editora. E-mail: jfernandoss@terra.com.br.

** Assistente social, doutora em Serviço Social pela Unesp-Franca/SP, Brasil; professora do Departamento de Serviço Social na mesma universidade, pós-doutora pelo Departamento de Sociologia da Universidade de Havana. E-mail: onildalves@uol.com.br. 


\section{Situando o tema: Cuba e o cenário sócio-histórico}

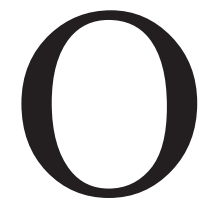

texto ora apresentado é parte da construção teórico-prática coletiva que vem sendo progressivamente produzida nos últimos quatro anos por meio do intercâmbio internacional Capes-MÊS-Cuba 098/2010 - AUXPE n. 157/2010 - firmado entre o curso de pós-graduação em Serviço Social da Unesp-Franca e o Departamento de Sociologia da Universidade de Havana. ${ }^{1} \mathrm{O}$ que se pretende, a seguir, tendo por base as condições objetivamente dadas pela ordem madura do capital, é apontar objetivamente alguns dos principais desafios atuais para o Trabalho Social cubano manter-se fiel à tradição revolucionária inaugurada na ilha em janeiro de 1959 (com todas suas conquistas e limites), processo esse trilhado a partir do levante popular liderado por Fidel Castro Ruz e de seu aprofundamento como transição socialista nos primeiros dois anos da década de 1960. Para tanto é preciso considerar as particularidades da sociedade cubana e sua trajetória, os caminhos concretamente trilhados pelo Trabalho Social em Cuba, seus múltiplos significados, suas peculiaridades em uma sociedade que ousou desencadear transformações estruturais dentro das condições históricas possíveis estabelecidas no início dos anos 1960.

Longe de demonizar ou idolatrar a rica, corajosa, única e exemplar experiência cubana em território latino-americano ${ }^{2}$, muito menos de assumir uma posição "intelectual-acadêmica" comprometida em avaliar "científica" e "equilibradamente" as particularidades de Cuba à luz de "teorias do conhecimento"

1. Projeto denominado "O Serviço Social no Brasil e em Cuba: trabalho e formação profissional a partir da década de 1960" composto por docentes e discentes das duas universidades (pós-graduação e graduação). O projeto se iniciou em 2011 com finalização prevista para dezembro de 2014. Equipe brasileira: professor dr. José Fernando Siqueira da Silva (coordenador), profa. dra. Raquel Santos Sant'Ana (vice-coordenadora), doutoras Onilda Alves do Carmo, Patrícia Soraya Mustafa, Edvânia Ângela de Souza Lourenço e Regina Soares Jurkewicz (membros bolsistas) e discentes de iniciação científica Ana Léa Martins Lobo (2011-13), Mariana Roque Pereira (2012-13), Cleyton da Silva Oliveira (2014) e Thiago Dehon de Souza (2014). Equipe cubana: profa. dra. Teresa Muñoz Gutiérrez (coordenadora), profa. dra. Clotilde Proveyer Cervantes (vice-coordenadora), profa. dra. Rebeca Ramos, profa. dra. Lourdes de Urrutia Barroso, prof. dr. Ernel Gonzales Mastrapa, profa. dra. Reina Fleitas Ruiz e profa. mestre Rosa Maria Voghon Hernández (os quatro últimos bolsistas).

2. Experiência essa não apenas digna de respeito, mas merecedora de absoluta solidariedade e apoio crítico comprometidos com a emancipação social e humana de homens e de mulheres. 
forjadas na cabeça de "pesquisadores brasileiros iluminados" (o que seria, no mínimo, de uma arrogância brutal), o que se pretende é perquirir a trama materialmente posta, analisá-la como acúmulo de forças sociais comprometido com a emancipação social. Em outras palavras, as observações que serão aqui explicitadas não pretendem impor à realidade uma racionalidade "científica" exterior a ela, manipulá-la como "coisa da lógica" (Marx, 2005), como especulação político-filosófica que a mensura, quantificando-a e catalogando-a a partir de uma lógica que lhe é estranha. Diferentemente disso, o que se pretende é oferecer algumas notas ontocríticas sobre o tema a partir de condições históricas objetivamente dadas, com base em um acúmulo coletivo possível possibilitado pelo convênio que se encerra em dezembro de 2014, mediadas por regras sociais que orientam a sociabilidade em curso (ou seja, a ordem do capital). Em outras palavras, trata-se de um contexto composto por ações concretas, materiais, como complexos sociais cuja ciência deve se debruçar para explicar a sua lógica (interna), como "lógica da coisa" (Marx, 2005, p. 39), para além de uma racionalidade "puramente científica" e exterior a ela, como "forma de vida, determinações de existência" (Marx, 1989, p. 410), como componente de uma totalidade social que não se explica pela simples extensão da ordem social em curso, mas que também não pode ser decodificada por um "mar de fragmentações singulares" justificadas pelas condicionalidades e pelas ações dos principais atores envolvidos na realidade cubana com suas especificidades no âmbito do Trabalho Social.

É preciso salientar que muitos dos problemas e conquistas que serão aqui sinteticamente dessecados fazem parte de uma trama mundial situada no campo da economia política burguesa, da reprodução ampliada do capital em sua fase madura (certamente monopólica, imperialista e financeira - Lenin, 2008; Hobsbawn, 1988, 1997; Chesnais, 1996; Harvey, 2003; Netto, 1992), comprometida em pôr e repor contradições que são estruturais, cada vez mais intensas e insolúveis dentro das fronteiras da sociedade capitalista (e isso não é diferente para a sociedade cubana, mesmo com suas conquistas). Tal cenário desafia, ao mesmo tempo, o Trabalho-Serviço Social em escala planetária, bem além dos limites de uma pequena ilha que ousou desencadear, a partir de condições históricas muito particulares, determinada transição socialista. Lukács é certeiro ao demarcar a prioridade ontológica da vida material e do papel relativo 
(embora fundamental) dos sujeitos históricos ativos na perspectiva da categoria da totalidade em Marx:

[...] o espiritual existe como algo não criado em si, não sugerido. Ou produz o ser material na medida em que o degrada a uma visão ou representação, ou o eleva a um conceito, não importa se junto com isso seja estabelecido um ser incognoscível e por isso objetivamente irrelevante. [...] O caráter post festum de todo conhecimento do ser é por isso um componente fundamental do método marxiano que brota da realidade, nele nada pode se expressar (nem deve) senão a tentativa de reproduzir no pensamento os processos reais segundo seu decurso efetivo, da maneira mais precisa e generalizada possível. [...] O positivismo e, sobretudo, o neopositivismo ocupam nesse desenvolvimento da filosofia um lugar especial somente na medida em que aparecem com a pretensão de assumir uma posição de perfeita neutralidade em todas as questões relativas à concepção de mundo, de deixar simplesmente em suspenso todo o ontológico e de produzir uma filosofia que remove por completo de seu âmbito o complexo de problemas referente àquilo que é em si, tomando-o como pseudoproblema, irrespondível por princípio. [...] (Lukács, 2010, p. 356, 375; 2012, p. 53-54).

O leitor deste artigo deve se propor a mergulhar em uma realidade cuja trajetória divergiu, até muito recentemente, da realidade dos países capitalistas cujos valores e princípios são marcados pelo individualismo extremo. Cuba não é e nunca foi um país comunista, embora tenha iniciado certo tipo de transição socialista que com certeza atentou contra o capitalismo (e isso, por si, já significou muito). O bloco socialista liderado pela ex-União Soviética, como sociedade pós-capitalista (Mészáros, 12/2/2002), não afetou e não poderia afetar a reprodução ampliada do capital e, portanto, não atingiu o comunismo (como estágio mais avançado do socialismo). A sociedade comunista não se objetivou até os dias atuais porque seu processo revolucionário exige amadurecimento (não espontâneo, portanto marcado pela luta de classes) das contradições internas do próprio capitalismo, uma construção sócio-histórica que carece de uma transição socialista e de uma revolução em escala mundial como havia alertado Marx. ${ }^{3}$ É

3. É curioso observar as "conclusões certeiras" da ciência burguesa e de seus ideólogos ao somente eternizarem a sociedade do capital. Augusto Comte já alertava sobre os "perigos dos preconceitos revolucio- 
exatamente por isso que Cuba e toda transição socialista se inserem em um cenário de rupturas com continuidades, acertos e erros, decisões historicamente possíveis, necessárias, não isoladas e limitadas por impasses objetivamente dados e mundialmente determinados. Destaca Marx (2009, p. 71):

Toda a emancipação política é a redução do homem, por um lado, a membro da sociedade civil, a indivíduo egoísta independente; por outro, a cidadão, a pessoa moral. Só quando o homem individual retoma em si o cidadão abstrato e, como homem individual - na sua vida empírica, no seu trabalho individual, nas suas relações individuais —, se tornou ser genérico; só quando o homem reconheceu e organizou as suas Forces propres (forças próprias) como forças sociais e, portanto, não separa mais de si a força social na figura da força política — [é] só então [que] está consumada a emancipação humana. [...].

A partir dessa base metodológica comprometida em reconstruir mentalmente, como lógica material-concreta, como processos particulares genuinamente humanos orientados pela perspectiva da totalidade social (Lukács, 2012, 2010), serão tecidas algumas observações sobre o Trabalho Social cubano.

\section{0 Trabalho Social cubano: avanços e ponderações críticas}

Como destacaram Carmo, Silva e Muñoz (2013), a palavra Trabalho Social não pode ser diretamente traduzida do espanhol ao português desconsiderando os universos e cenários sócio-históricos concretamente dados pela realidade cubana. Os termos Trabalho Social e trabalhador social em Cuba tiveram um sentido próximo da realidade e do mundo capitalista até o triunfo do Movimento Guerrilheiro 26 de julho liderado por Fidel Castro. Tratava-se, até 1959, no

\footnotetext{
nários" após o triunfo das revoluções Industrial e Francesa. Para estes a sociedade burguesa é eterna enquanto o feudalismo foi uma forma histórica superada por "empreendedores individuais" e o comunismo uma "abstração esquerdista cientificamente não comprovada" (superada pelas experiências falidas do Leste Europeu). Sob esse patamar, a ilha de Cuba e alguns países latino-americanos são aberrações esquerdistas e populistas. Para exemplificar essa visão social de mundo regada por simplismos e por ideologias burguesas com ênfase industrial-pecuarista-agrária, consultar artigo publicado pela senadora Kátia Abreu (Folha de S.Paulo, 16 ago. 2014, p. 10).
} 
sentido mais estrito, de uma profissão com demandas socialmente geradas e expressas na divisão social do trabalho no mundo capitalista (Iamamoto, 1994, 2007) com papel social particular: o trato do que se convencionou caracterizar como "questão social", expressão direta do pauperismo explicado pela "lei geral da acumulação capitalista" (Marx, 1984). Portanto, uma profissão demandada pelo mercado de trabalho capitalista, como espaço reconhecido enquanto tal (aspecto decisivo para a gênese do Trabalho Social/Serviço Social como profissão no final do século XIX), ainda que frequentemente estivesse articulado a ações caritativas mantidas por ações religiosas. ${ }^{4}$ Em Cuba, com suas particularidades, o que predominou até o início dos anos 1960 foi um programa de formação profissional com enfoque "salubrista", de perfil filantrópico e assistencialista (Muñoz e Urrutia, 2004; Carmo et al., 2012).

Com o triunfo da revolução popular em janeiro de 1959 e seu aprofundamento no sentido de uma transição socialista nos anos seguintes, o sentido do Trabalho Social e o papel dos trabalhadores sociais passaram por mudanças significativas 5 . Ao promover amplas transformações sociais na Ilha, comprometidas com o acesso a recursos fundamentais e a níveis crescentes de emancipação social (saúde, educação, habitação, cultura e condições dignas de trabalho, entre outros aspectos), o termo Trabalho Social assumiu um caráter amplo, de militância geral, como compromisso social de todo povo cubano com a eliminação dos processos sociais que mantiveram o país primeiro sob o domínio colonial espanhol e posteriormente sob o domínio imperialista norte-americano. Portanto, o Trabalho Social em Cuba adquiriu, mais recentemente, um sentido de tarefa social, de luta contra situações de opressão, de defesa revolucionária pela melhoria das condições de vida dos cubanos e compromisso social com a revolução em outros territórios do planeta. Em Cuba, essa perspectiva é latente não apenas em relação aos trabalhadores sociais assistentes

4. Destaca José Paulo Netto (1992, p. 69): “A profissionalização do Serviço Social não se relaciona decisivamente à "evolução da ajuda", à "racionalização da filantropia" nem à "organização da caridade"; vincula-se à dinâmica da ordem monopólica".

5. Vale lembrar com cuidado que o país não adentrou a uma transição socialista por um passe de mágica, por um gesto abnegado, mas por meio de um processo maturado nos primeiros três anos após a queda de Fulgencio Batista. Foram assumidas coletivamente, gradativamente, ações e opções lideradas pelo governo cubano que aproximaram o país do bloco socialista da época em tempos de Guerra Fria. 
sociais e militantes, mas também para outras categorias profissionais (médicos e professores, por exemplo). Trata-se, para o projeto revolucionário, de um compromisso com a formação não apenas técnico-profissional, teórico-metodológica, mas, principalmente, ético-política (Barroco, 2001; Iasi, 2007; Guerra, 1995), como homens e mulheres socialmente comprometidos com ideais emancipatórios para além dos valores e princípios mercadológicos. Diante desse contexto, as terminologias Trabalho Social e trabalhador social assumiram outras formas para além daquelas que remetiam aos profissionais (propriamente ditos) antes de 1959, desenvolvendo formações profissionais voltadas para áreas específicas e para objetivos e tarefas imediatas enfrentadas pelo país.

Um primeiro grupo de trabalhadores sociais do período pós-revolucionário cubano foi organizado pela Federação das Mulheres Cubanas (FMC), liderada pela guerrilheira e revolucionária Vilma Espín de Castro (companheira de Raúl Castro, já falecida). Tal organização exerceu papel importante na formação de voluntárias comprometidas com os ideais da Revolução Cubana (como voluntárias de esquerda), responsáveis, entre outras coisas, por ações que ampliavam a atuação das mulheres na sociedade e nos espaços de trabalho (para além do espaço do lar), crítica ao machismo, atuações junto às famílias econômica, cultural e socialmente debilitadas oriundas do período pré-revolucionário, criação dos Círculos Infantis que atuavam com crianças enquanto os pais exerciam atividades trabalhistas, bem como forte e ampla atuação com núcleos familiares e comunidades nos duros anos 1990. Trata-se, aqui, de trabalhadores sociais militantes, de perfil técnico-voluntário, comprometidos em levar a cabo os compromissos sociais impostos à construção da nova sociedade cubana.

Um segundo grupo de trabalhadores sociais é formado por aqueles que atuam nas áreas de saúde, educação, assistência e seguridade social, com um perfil técnico-profissional. Entre os anos 1971 e 1998 a formação deles era feita pelo Ministério da Saúde que fundou sua primeira escola em 1971, em Camaguey. O mesmo órgão estatal criou, em 1972, a Escuela de Trabajadores Sociales de Psiquiatria junto ao Hospital Psiquiátrico de Havana, de nível médio (Muñoz e Urrutia, 2004). Tais profissionais atuam em demandas específicas existentes em policlínicas, hospitais, escolas, assistência e previdência social, envolvendo famílias, crianças, adolescentes, homens, mulheres e idosos. Esse espaço sócio-ocupacional, mais próximo do que se conhece sobre a atuação dos 
assistentes sociais brasileiros, permanece atual, em metamorfose e constante reorganização interna a partir dos inúmeros problemas reaquecidos na Ilha após as reformas de mercado inevitáveis no atual contexto mundial.

Estas limitaciones que se han señalado en la formación de Técnico Medio en Trabajo Social que se gradúa en las escuelas del Ministerio de Salud Pública, trae como resultado déficit en la formación teórico metodológica, y en el conocimiento de los diferentes campos de acción en el que el trabajador social debe desempeñar su labor. Pero es indiscutible el papel jugado por esta institución, en el reconocimiento de la necesidad de este profesional, agrupada en la Asociación de Trabajadores Sociales de la Salud, la que mantiene la celebración sistemática de Congresos en el país, y ha fomentado el intercambio con profesionales de América latina y de otros países. (...) (Muñoz e Urrutia, 2004, p. 56).

Uma terceira tendência de trabalhadores sociais se desenvolveu entre 1998 e 1999, com os longos anos de recessão. Após solicitação da Federação de Mulheres Cubanas, do Ministério do Trabalho e Seguridade Social e do Ministério do Interior, o Ministério da Educação Superior abriu uma Licenciatura em Sociologia com especialização em Trabajo Social na Universidade de Havana (Muñoz e Urrutia, 2004, p. 64-65). Nota-se, aqui, um importante vínculo universitário na era pós-revolucionária da formação de trabalhadores sociais, momento em que uma quantidade significativa de estudantes trabalhadores ingressou na universidade. Experiências do gênero foram também vividas nos cursos de mestrado em Trabajo Comunitário na Universidad de Camagüey e de Trabajo Social Comunitario na Universidad Central Martha Abreu de Las Villas. A proposta se estendeu para diferentes municípios de Cuba, como parte da universalização do ensino superior que se produziu na Ilha a partir de 2000. O que se observa é que esse grupo de trabalhadores sociais com experiência universitária obteve uma formação universitária diversa do segundo grupo com formação técnica oferecida fora dos espaços universitários. É preciso destacar, ainda, que as crescentes dificuldades sociais da Ilha após a queda da União Soviética e do bloco pós-capitalista por ela liderada inegavelmente estimularam a recriação de estratégias, também profissionais, para lidar com a desigualdade social inicialmente estimulada pelo amargo remédio — o turismo - 
responsável por uma massa significativa de ingressos financeiros em Cuba a partir dos anos 2000.

Desde então, como desdobramento da crise que já afetava Cuba por mais de dez anos, foi iniciado um programa estatal criado em conjunto com a União dos Jovens Comunistas estimulado pelas Escolas de Formação Emergente de Trabalhadores Sociais. Esse programa atendeu demandas específicas comprometidas em oferecer a inúmeros jovens uma formação básica (de não mais do que dois meses). Tal iniciativa atendia as demandas emergenciais junto aos segmentos mais jovens que cresceram e viveram intensamente os anos de crise e seus impactos na vida dos cubanos. Essa quarta tendência do Trabalho Social em Cuba retomou e aligeirou a formação técnica, não porque desejasse empobrecê-la (e não haveria como enriquecê-la no espaço de tempo dedicado a essa capacitação), mas porque tinha um objetivo certeiro e pragmático: de um lado oferecer um espaço de formação à juventude que sofria claros impactos dos duros anos de crise econômica e, de outro, fazer um levantamento sobre as necessidades das famílias cubanas.

O que interessa destacar aqui é que a trajetória do que se convencionou caracterizar como Trabalho Social em Cuba passou por instabilidades significativas, idas e vindas que transitaram por caminhos muito heterogêneos, tortuosos, vinculados às necessidades imediatas enfrentadas pelo país. Ainda que seja necessário reconhecer o esforço para romper com as bases do que mundialmente denominou-se como Serviço Social-Trabalho Social tradicional (Netto, 1991, 1992), com contribuições certeiras no campo ético-político e com ações práticas extremamente organizadas e criativas orientadas por valores socialistas (Guevara, 1965), a formação teórica dos trabalhadores sociais cubanos permaneceu fora das universidades e sem um debate denso que pudesse auxiliar a produção de conhecimentos genuinamente ontológica (como práxis profissional intensa), efetivamente teórico-prática, resgatando e aproveitando o rico legado revolucionário coletivamente construído em Cuba. É nesse sentido que o Trabalho Social permaneceu predominantemente técnico (ainda que com lampejos de proximidade com o espaço universitário), fato que, todavia, não lhe conferiu, em si e por si, inferioridade (ainda que a formação teórico-prática tenha ficado limitada a um tempo curto de duração), mas com certeza limitou 
o acesso a outras fontes de informações (histórico-teórico-filosóficas) que poderiam enriquecer o conhecimento prático-técnico acumulado.

Muchos son los actores sociales involucrados en la institucionalización del Trabajo Social en el país, y que en determinados momentos históricos han tenido una mayor o menor presencia. Pioneros en el impulso de la profesión luego en 1959, lo fueron: la Federación de Mujeres Cubanas y el Ministerio de Salud Pública, también se suman a estos esfuerzos otras organizaciones sociales, como los Comités de Defensa de la Revolución, por ejemplo, y las Direcciones de Asistencia Social de Ministerios como Trabajo y Seguridad Social, del Interior y el Instituto de La Vivienda. Ya a finales de la década de los 90 para darle continuidad a este proceso se incorporan las Universidades y el estado Cubano a través de las organizaciones juveniles, y como parte de un grupo de Programas Sociales creados para los jóvenes por iniciativa del Comandante en Jefe Fidel Castro Ruz. (...) (Muñoz e Urrutia, 2004, p. 46).

Diante do exposto, algumas questões se apresentam como centrais para retomar o rico legado do Trabalho Social cubano e adensá-lo em duros tempos de crise que a sociedade cubana experimenta na atualidade. As dificuldades internas da Ilha, algumas delas resultado direto das investidas do capital transnacional e do embargo econômico dos Estados Unidos que dura mais cinquenta anos, se colocam como desafios a serem enfrentados pela sociedade cubana, tendo presente que a crise estrutural do capital atinge outras áreas do planeta de forma profunda. ${ }^{6} \mathrm{~A}$ atual sociabilidade do capital produz, com isso, a depreciação brutal de direitos, a precarização e a intensificação do trabalho, a redução do trabalho vivo e o aumento do desemprego, o aprofundamento de um padrão de acumulação mundial que avilta a vida genuinamente humana, destrói os recursos naturais, põe em xeque a vida no planeta, a própria espécie humana (Mészáros, 2002; Antunes, 1999, 2000; Chesnais, 1996; Harvey, 2003, 2011).

6. O covarde bloqueio econômico imposto pelos Estados Unidos a Cuba tem sofrido recentes inflexões que não podem ser desprezadas (simbolizadas, recentemente, pela liberação de presos políticos de ambos os lados). Todavia, segue firme e depende de decisões que envolvem o Congresso Nacional estadunidense (de maioria republicana). Não restam dúvidas que o adensamento das reformas econômicas na Ilha afetará diretamente o Trabalho Social cubano e imporá desafios que reforçam as observações destacadas neste artigo. 
Sendo assim, alguns aspectos precisam ser destacados com o objetivo de forcejar em uma direção social que, ao mesmo tempo, rejeita as limitações cientificistas burguesas presentes não somente em sociedade capitalistas maduras (e em seus centros de formação e prática-institucional), mas também em projetos que ousaram questionar o capitalismo por meio de alternativas possíveis de transição socialista.

Em primeiro lugar é preciso esclarecer as diferentes denominações teórico-práticas do Trabalho Social cubano objetivamente em curso (com seus desdobramentos sociopolíticos), orientações essas que foram sendo gradativamente desenvolvidas antes de 1959 e posteriormente com o triunfo da revolução liderada por Fidel Castro (na perspectiva há pouco esboçada). Isso é importante não para desqualificar o que já foi construído, mas para demarcar suas diferenças, o sentido de cada uma dessas perspectivas, seus pontos de intersecção capazes de estimular um diálogo produtivo, sua unidade na diversidade. Nesse sentido, é necessário reconhecer, como em qualquer realidade (inclusive a brasileira), que existem particularidades de inserção sócio-ocupacional dos trabalhadores sociais ou ainda, no caso de Cuba, há uma clara tendência de associar o Trabalho Social à militância geral atribuída a todos os indivíduos (para além das fronteiras profissionais). Isso não significa, em absoluto, que devamos fracioná-lo em suas expressões profissionais ou militantes, mas destacar a unidade dessas áreas de atuação com inserções e demandas particulares. Nota-se aqui uma diferença nada desprezível, uma vez que, por exemplo, o trabalhador social de saúde difere substancialmente do trabalhador social na saúde, ou seja, na segunda denominação o Trabalho Social não se explica unicamente por sua especificidade interventiva, mas se particulariza nela, considerando suas demandas e sua inserção na totalidade social.

Em segundo lugar, essa primeira observação se desdobra em outra significativa: a possibilidade de criação dos cursos de graduação e de pós-graduação universitários, tendo as universidades públicas cubanas como referências auxiliares importantes para superar um conhecimento puramente técnico e setorizado, por áreas de especialidade, formação esta assumida e ministrada, até hoje, pelas organizações estatais que se vinculam ao Trabalho Social em Cuba. Vale destacar que esse procedimento não deve desconsiderar o conheci- 
mento teórico-prático acumulado por esses segmentos, inclusive sua dimensão técnica e ética, mas ser orientado por uma perspectiva de totalidade que reafirme a transição socialista e seja capaz de ampliar os horizontes analíticos e formativos (em geral) dos trabalhadores sociais. Ao mesmo tempo, seria possível recriar espaços de interlocução entre a dimensão interventiva e os grupos mais próximos às universidades não para valorizar um academicismo estéril ou reforçar o abismo entre os que pensam e os que fazem, mas para qualificar a práxis profissional dos trabalhadores sociais e dos docentes que se inserem em áreas particulares de atuação como unidade diversa entre teoria e prática na formação profissional. Esse cenário não apenas redimensionaria a formação dos novos trabalhadores sociais cubanos como também permitiria aos que já foram preparados profissionalmente, dentro de suas áreas específicas, em seus centros especializados de formação, enriquecerem o saber já acumulado ocupando um espaço tradicionalmente vinculado à produção de conhecimentos: a universida$d e$. Nota-se, aqui, que não se trata de um problema exclusivo do Trabalho Social cubano, mas do Trabalho Social/Serviço Social mundial praticado sob as condições objetivas determinadas socialmente pelo capitalismo, na sua fase madura, em diferentes países do globo.

Em terceiro lugar, nenhuma das alternativas apontadas poderia obter sucesso sem um elemento central: a ênfase em uma formação profissional que tenha um perfil intelectual-generalista insistindo em conteúdos relacionados às Ciências Humanas e Sociais (História, Filosofia, Política, Economia, Sociologia entre outros), orientados sob a perspectiva de totalidade (Lukács, 2010, 2012), de reconstrução de categorias cuja lógica faz parte da vida material, o que não significa abdicar da dimensão técnica-operativa (ao contrário), mas submetê-la a uma formação teórico-crítica capaz de formar intelectuais que pensam e fazem criticamente. Nega-se, aqui, de forma simultânea, o praticismo que afeta cotidianamente os profissionais "da prática" (muito comum no Brasil), todo e qualquer equívoco que tenda a valorizar a superioridade da "sapiência teoricista" dos acadêmicos especulativamente iluminados, bem como perspectivas centradas em teorias do conhecimento pós-modernas comprometidas com o ecletismo e com o pragmatismo que tendem a identificar a formação profissional com o manejo "competente" de recursos teóricos construídos à revelia 
da realidade objetivamente dada, na mente especulativa de quem investiga, como um conhecimento estranho à realidade, como algo externo a ela e a quem o maneja. Vale destacar que nesse aspecto específico a realidade cubana possui um passo adiante em relação a outros países cuja formação quase sempre se centrou em um valor diariamente universalizado pelo mundo do capital: $o$ individualismo extremo. Ainda que as sociedades que ousaram desencadear uma transição socialista também sofram com entulhos presentes em formas inferiores de sociedade (e não poderia ser diferente, também porque o mundo é capitalista), inúmeras experiências coletivas e de compromisso das universidades com "os de baixo" foram desenvolvidas em sociedades pós-capitalistas incentivando outros valores sociais de extrema valia e ausentes institucional e individualmente em países de capitalismos tardios, como é o caso do Brasil (salvo raríssimas exceções, ilhas de resistência nas diferentes esferas da vida social). ${ }^{7}$

Em quarto lugar essa alternativa permitiria uma retomada de uma tradição teórica já presente na sociedade cubana: a tradição socialista e a perspectiva comunista orientada por niveis crescentes de emancipação social tendo como horizonte a emancipação humana. O faz, todavia, critica e autocriticamente, valorizando o diálogo entre os diferentes sem reforçar procedimentos ecléticos, debatendo firmemente com os atalhos oferecidos pelas tendências pós-modernas centradas na fragmentação da vida social, na busca da verdade do "miúdo", em sua dinâmica única, isolada, negadora dos procedimentos empenhados em conhecer a lógica dos processos materiais, mas também comprometido em remover os entulhos positivistas incorporados pelos marxismos, os equívocos stalinistas que pulverizaram por dentro a teoria social de Marx e de parte de sua tradição. ${ }^{8}$

7. Um "leitor atento" perguntaria na sua nobre sapiência defensora do "acesso democrático" aos bens de consumo: "Mas em que tais sociedades serviriam para mim e para meu sucesso? Não existe nada lá, as pessoas ganham pouco, o governo fica com tudo, faltam produtos básicos e elas não têm o direito de ir e de vir!". A resposta a esses preconceitos e à ignorância contida nessas afirmações situadas na absoluta imediaticidade da vida social seria clara: "Em nada serviria para você!”. Certamente o projeto societário aqui defendido é outro; a referência social e a direção social são outras, guardados os acertos e erros históricos individuais-sociais, históricos-humanos, típico de grupos que ousam mirar a emancipação social e a questionar o individualismo extremo.

8. Vale destacar que a experiência cubana não pode ser analisada como uma simples extensão da revolução socialista de 1917, da União Soviética e de seus inúmeros desvios na era stalinista, embora esse vín- 
Destaca-se aqui o que nos parece essencial para reafirmar os valores revolucionários: atualizá-los coerentemente ao longo dos desafios históricos cotidianamente enfrentados, continuar formando crianças, jovens, adultos e anciãos com os valores genuinamente humanos comprometidos com uma transição socialista necessária a sociedades pós-capitalistas, sobretudo em duros tempos de solidão e de isolamento forçado.

Em quinto e último lugar, tal caminho não apenas está afinado com uma renovação progressista do Trabalho Social cubano, tendo Marx e sua tradição como referências necessárias (certamente não únicas) à crítica à sociedade do capital, à sua organização societária apoiada na apropriação privada da riqueza social, como também endossa as tendências mais críticas do Trabalho Social em escala mundial, as "ilhas de resistência" latino-americanas e de outros continentes. Reforça, ainda, projetos sociais necessários situados muito além das fronteiras do Trabalho Social/Serviço Social, diversos daquelas linhas comprometidas com projetos sociais reformistas e dóceis com o processo de mundialização do capital em curso e suas nefastas consequências para a recriação do pauperismo absoluto e relativo no centro e na periferia do capitalismo mundial. Portanto, contrárias ao individualismo extremo declarado nas ações efetivas dos falcões republicanos e de suas expressões em Miami ou dos falcões-sabiás reprodutores de um canto sedutor, "belíssimo", que anestesia os ouvidos e as almas (críticas) em nome da "democracia", do "equilíbrio" e da "ponderação": "humanizemos o capital e reorganizemos o capitalismo!".

\section{Pontuações inconclusivas: sem ilusões/abstrações, mas com utopias e horizontes}

A sobrevivência do Trabalho Social crítico cubano e de todos aqueles existentes em outras regiões do globo (comprometidos com os pontos aqui defendidos) depende de alguns elementos que vão muito além das fronteiras

\footnotetext{
culo tenha sido decisivo para Cuba. Como experiência particular, genuinamente popular e latino-americana, o triunfo do Movimento 26 de Julho em 1959, seus acertos e erros, devem ser analisados a partir de condições sócio-históricas específicas.
} 
dessa profissão mundialmente constituída a partir dos últimos anos do século XIX. Endossando uma trilha que nega ilusões ao mesmo tempo em que reafirma uma utopia que orienta a busca pela emancipação social humana na luta real, cotidianamente dada e apenas realizada quando objetivada por meio de ações reais capazes de alterar o curso da vida social, é importante salientar alguns aspectos norteadores para a continuidade do debate:

1. O fôlego do Trabalho Social/Serviço Social crítico cubano está diretamente vinculado à retomada, em escala mundial, de um projeto de esquerda de perfil claramente anticapitalista, comprometido com a construção de projetos socialistas avessos a qualquer raciocínio especulativo, idealista e a-histórico. Essa retomada, portanto, deve ser absolutamente embebida por história e por historicidade, pelas condições concretas e objetivamente dadas à possibilidade real de novas transições socialistas fiéis à emancipação humana.

2. A afirmação do Trabalho Social crítico em Cuba deve contar com uma interlocução genuína com Marx e os marxistas contemporâneos (dentro e fora da construção teórico-prática-crítica do Serviço Social/Trabalho Social mundial). Nesse contexto, o diálogo com a tradição dialética do Serviço Social brasileiro (especificamente aquela denominada por Netto (1991) como "intenção de ruptura") é particularmente relevante e altamente proveitoso aos segmentos envolvidos com o avanço e a consolidação do Serviço Social/Trabalho Social crítico em escala planetária. É preciso destacar, ainda, a necessidade do debate consistente com outras orientações teóricas diversas da marxiana, da sua tradição, portanto, a ênfase em um debate plural, conhecedor do diferente, de seus principais argumentos e teses, ainda que isso, em hipótese alguma, signifique endossar o caminho do ecletismo.

3. Vale ressaltar, também, a necessidade de recusar duas tendências hoje reatualizadas no âmbito do Trabalho Social/Serviço Social em toda América Latina também no campo das esquerdas: a) por um lado o revigoramento do militantismo que tudo atribui à profissão, como se a mesma possuísse a "varinha mágica" para combater a desigualdade social e "conscientizar" as massas, conferindo ao Trabalho Social/Serviço Social uma tarefa que jamais poderia cumprir por si mesmo; b) por outro lado, seu oposto, a tendência de descaracterizar o Trabalho Social/Serviço Social como uma instância útil ao acúmulo de forças 
(com suas possibilidades e limites objetivamente dados), já que se caracterizaria como uma esfera contaminada por imperfeições estruturalmente determinadas pelo mundo do capital (sobretudo pela sua versão reformista), subserviente aos interesses das classes sociais detentoras do capital e suas frações. Não se trata, aqui, de superestimar ou subestimar as profissões (entre elas o Trabalho Social/Serviço Social), mas de reconhecê-las como espaços contraditórios, seus limites como profissões nascidas, edificadas e tecidas sob as condições sócio-históricas determinadas pela apropriação privada da riqueza social socialmente produzida. A crítica certeira à propriedade privada, seus desdobramentos no campo do trabalho (alienado estranhado) e a suas modernas consequências teórico-práticas de inspiração toyotista (precarização, redução brutal de direitos e do trabalho vivo, entre outras características), deve balizar toda práxis profissional sem esperar dela o que não pode realizar, mas sem perder importantes espaços de resistência e de acúmulo de forças que também com ela o campo das esquerdas pode se beneficiar.

4. Nesse sentido, o compromisso com uma direção social humanamente emancipadora, fiel à tradição revolucionária, não pode descartar a luta por dentro das contradições recriadas pelo mundo do capital, ocupando diferentes esferas que compõem a vida social. O nosso compromisso profissional como trabalhadores sociais/assistentes sociais não é um compromisso endógeno, messiânico e exclusivo. Trata-se de uma fidelidade com a emancipação humano-social de homens e mulheres historicamente situados, portanto como sujeitos ativos e relativos, direção essa nada afeita a diferentes formas de abstração, de idealização da vida real vivida por seres sociais de carne e osso. Sendo assim, o compromisso profissional, mediado por essa esfera, vincula-se primeiramente à emancipação humana e à realização real de seus objetivos. O Trabalho Social/Serviço Social deve ser pensado e praticado sob tais bases, com todos os limites e contradições concreto-materiais aqui contidos (o que faz toda a diferença para as pequenas e grandes coisas, dentro e fora das profissões). Com certeza a radicalização da transição socialista rumo à sociedade comunista humanamente emancipada imporá a redefinição radical do Trabalho Social/ Serviço Social e, em estágios mais avançados, sua extinção como profissão originalmente concebida a partir da era monopolista/imperialista do capital. 
5. Especificamente em relação a Cuba, não há como negar a concretude das mudanças em curso na Ilha (principalmente após a crise dos anos 1990 e da queda da União Soviética), cenário esse fortemente agravado por mais de cinquenta anos de bloqueio econômico imposto pelos Estados Unidos (em curso). Embora esse aspecto não explique, por si só, os problemas enfrentados pela Ilha, é fato que ele agiu decisivamente para os destinos recentes do país após a falência da economia planejada do bloco socialista do Leste Europeu até então existente. Isso exige, por um lado, a tomada de consciência (sem ilusões) sobre os desafios atuais e o que pode vir daqui em diante. Nesse contexto, reorganizar o Trabalho Social/Serviço Social a partir de bases que auxiliem a resistência, a afirmação e a reconstrução da transição socialista nos dias atuais, sob suas condições reais (portanto sem ilusões). Como destacam Carmo, Silva e Muñoz (2013, p. 300 e 301),

há de se reconhecer a complexidade social que atualmente vivencia a sociedade cubana, contexto que demanda deste profissional um maior compromisso ético-político orientado por níveis de justiça e equidade social — na direção de níveis crescentes de emancipação social —, como passo imprescindível para o aprofundamento do processo revolucionário iniciado em janeiro de 1959. Isso, por si só, justifica uma saída coletiva que comece pelo diálogo latino, centro-americano e caribenho. Nesse contexto se inscreve o necessário e cuidadoso debate entre o Serviço Social brasileiro e o "Trabajo Social" cubano, tendo como referência a constituição de momentos e espaços emancipatórios. Para tanto, a adesão a projetos societários mais amplos que congreguem as forças sociais heterogêneas daqueles que vivem da venda da sua força de trabalho, tendo a emancipação humana como referência inegociável, é uma orientação imprescindível. Ao mesmo tempo, é preciso não vacilar em relação ao marco teórico que deve sustentar estruturalmente esse debate: a teoria social de Marx.

Fora desse contexto, o debate tende a empobrecer-se entre os trabalhadores sociais cubanos, descartando um rico conhecimento teórico-prático acumulado (como seus ganhos e perdas), sobretudo a partir do triunfo popular de 1959 e do aprofundamento socialista que orientou Cuba no início dos anos 1960. Perde, também, o Trabalho Social/Serviço Social genuinamente crítico comprometido como níveis crescentes de emancipação social, ao desconsiderar a 
rica, peculiar e mais intensa experiência latino-americana no campo da transição socialista e do pós-capitalismo: a experiência cubana.

\section{Recebido em 26/8/2014 - Aprovado em 24/11/2014}

\section{Referências bibliográficas}

ABREU, Kátia. A falência bolivariana. Folha de S.Paulo, São Paulo, p. 10, 16 ago. 2014.

ANTUNES, Ricardo. Adeus ao trabalho? Ensaios sobre as metamorfoses e a centralidade do mundo do trabalho. 6. ed. São Paulo: Cortez; Campinas: Ed. da Unicamp, 1999.

. Os sentidos do trabalho: Ensaio sobre a afirmação e a negação do trabalho.

3. ed. São Paulo: Boitempo, 2000.

BARROCO, Maria Lúcia Silva. Ética e Serviço Social: fundamentos ontológicos. São Paulo: Cortez, 2001.

CHESNAIS, François. A mundialização do capital. São Paulo: Xamã, 1996.

CARMO, Onilda Alves do; SILVA, José Fernando S. da; MUÑOZ T. G. Serviço Social e Trabajo Social: tendências e perspectivas no Brasil e em Cuba. In: LOURENÇO, Edvânia Ângela de Souza. O avesso do trabalho III. São Paulo: Outras Expressões, 2013. p. 279-302

CARMO, Onilda Alves do et al. O trabalho social em Cuba e os desafios para sua institucionalização no atual contexto. In: ENPESS, 13., Anais..., CFESS, Juiz de Fora, 2012. CUBA. Caceta Oficial de la Republica de Cuba. Havana, Ministerio de Justicia, n. 30, p. 329, 21 set. 2011.

GUERRA, Yolanda. A instrumentalidade do Serviço Social. São Paulo: Cortez, 1995.

GUEVARA, Ernesto Che. El socialismo y el hombre en Cuba. Discurso proferido em 12 de março de 1965. Disponível em: <http://www.marxists.org/espanol/guevara/65-socyh.htm>. Acesso em: 20 dez. 2012. 
HARVEY, D. Condição pós-moderna. Tradução Adail Ubirajara Sobral e Maria Stela Gonçalves. São Paulo: Loyola, 2003.

. O enigma do capital e as crises do capitalismo. São Paulo: Boitempo, 2011.

HOBSBAWN, E. J. A era dos impérios (1875-1914). 3. ed. Rio de Janeiro: Paz e Terra, 1988.

. A era do capital (1848-1875). 5. ed. Rio de Janeiro: Paz e Terra, 1997.

IAMAMOTO, Marilda Villela. Renovação e conservadorismo no Serviço Social: ensaios críticos. São Paulo: Cortez/Celats, 1994.

Serviço Social em tempo de capital fetiche: capital financeiro, trabalho e questão social. São Paulo: Cortez, 2007.

IASI, Mauro. Ensaios sobre consciência e emancipação. São Paulo: Expressão Popular, 2007.

LENIN, V. I. O imperialismo: fase superior do capitalismo. Tradução Leila Prado. São Paulo: Centauro, 2008.

LUKÁCS, G. Para uma ontologia do ser social I. São Paulo: Boitempo, 2012.

. Prolegômenos para uma ontologia do ser social. Tradução de Carlos Nelson Coutinho. São Paulo: Boitempo, 2010.

MARX, Karl. Capitulo inédito de O capital: resultados do processo de produção imediata. São Paulo: Moraes, 1985.

. Crítica da filosofia do direito de Hegel. São Paulo: Boitempo, 2005.

. Manuscritos econômico-filosóficos. São Paulo: Boitempo, 2004.

. O capital: crítica da economia política. São Paulo: Abril Cultural, 1983. L. 1, v. 1, t. 1 .

. O capital: crítica da economia política. São Paulo: Abril Cultural, 1984. L. 1, v. 1, t. 2 .

. O método da economia política. In: FERNANDES, Florestan (Org.). Marx e Engels: história. 3. ed. São Paulo: Ática, 1989. [Textos originais de Marx e Engels.]

. Para a questão judaica. São Paulo: Expressão Popular, 2009.

; ENGELS F. A ideologia alemã. São Paulo: Boitempo Editorial, 2007. [Edição completa.] 
MARX, Karl. O Manifesto do Partido Comunista. Prólogo de José Paulo Netto. São Paulo: Cortez, 1998.

MÉSZÁROS. István. Para além do capital. São Paulo: Boitempo, 2002. p. 605-980. . Programa Roda Viva: entrevista. São Paulo: TV Cultura, 12 fev. 2002.

MONTAÑo, Carlos. A natureza do Serviço Social: um ensaio sobre sua gênese, a "especificidade" e sua reprodução. São Paulo: Cortez, 2007.

MUÑOZ, Teresa Gutiérrez; URRUTIA, Lourdes Barroso. El desarrollo del Trabajo Social en Cuba: profesionalización y práctica. Trabajo Social en Cuba y Suecia. Havana: Ministerio de Educación Superior-Talleres Gráficos de Geocuba, 2004. p. 45-67

NETTO, José Paulo. Capitalismo monopolista e Serviço Social. São Paulo: Cortez, 1992.

. Ditadura e Serviço Social: uma análise do Serviço Social no Brasil pós-64. São Paulo: Cortez, 1991.

. O Serviço Social e a tradição marxista. Serviço Social \& Sociedade, São Paulo, n. 30, p. 89-102, abr. 1989.

SILVA, José Fernando Siqueira da. Serviço Social: razão ontológica ou instrumental? Katálysis, Florianópolis, v. 16, n. 1, 2013a.

. Serviço Social: resistência e emancipação? São Paulo: Cortez, 2013 b.

SILVA, J. F. S. da; SANT’ANA, R. S.; LOURENÇO, E. A. de S. (Orgs.). Sociabilidade burguesa e Serviço Social. Rio de Janeiro: Lúmen Juris, 2013. 